\title{
Veterinary Education and Interaction in Veterinary Education
}

\section{Heli I. Koskinen*}

Faculty of Veterinary Medicine, University of Helsinki, Finland

In the field of educational research veterinary education has minority status. There is one international scientific journal, the Journal of Veterinary Medical Education that has taken the responsibility to publish papers dealing with veterinary education. Moreover, many veterinary educators have published their papers in journals dealing with special focus (radiology, pathology etc.). It is gratifying that journal like Veterinary Science and Technology with its emphasis of general issues in the field of veterinary medicine now publish this special issue.

Under term "veterinary education" many research lines can be adopted. It should be taken seriously that in veterinary schools adult learners are involved. Nowadays, it is believed that adults are selfdirected learners with their life experiences differed from children in schools. From the perspective of educational theory constructivist learning paradigm has widely accepted as a leading theory. It emphasizes the learning of an individual, his or hers own knowledge constructs. Learning is a product, which is constructed during participation in learning situations together with teachers and other students. Without a learning environment with interaction possibilities learning cannot take place. In constructivist framework not only a product, but also a process is important.
Constructivist paradigm has had an effect on veterinary education. Many veterinary educators have established learning environments full of interaction activities, and then evaluated the outcomes expected. This is a product approach. As a consequence of this line many quantitative research designs are released. Alternatively, also the process in learning environments can be studied. Learning situations vary widely, but they have one trait above all. In all learning situations interaction exists. It is veterinary educators' responsibility to study this interaction much more.

In this issue qualitative research design has been advocated. Practically, it might mean descriptive approach by profiling of animal protection course. However, qualitative research design is much more than a course description. It is useful to dive into the world of interaction between veterinary students and their teachers by real participating perspective. Observation is one method to create a deep knowledge about learning situations, and to collect students' learning experiences. These learning experiences are essential to next learning experiences, and the quality of learning.
*Corresponding author: Heli I. Koskinen, Faculty of Veterinary Medicine, University of Helsinki, Finland, E-mail: hikoskin@mappi.helsinki.fi

Received August 04, 2012; Accepted August 06, 2012; Published August 08 2012

Citation: Koskinen $\mathrm{HI}$ (2012) Veterinary education and interaction in veterinary education. J Veterinar Sci Technol S4:e001. doi:10.4172/2157-7579.S4-e001

Copyright: (c) 2012 Koskinen HI. This is an open-access article distributed under the terms of the Creative Commons Attribution License, which permits unrestricted use, distribution, and reproduction in any medium, provided the original author and source are credited. 